\title{
Postprandial gall bladder motility and hormone release during intermittent and continuous subcutaneous octreotide treatment in acromegaly
}

\author{
M F J Stolk, K J van Erpecum, H P F Koppeschaar, W I de Bruin, J B M J Jansen, \\ C B H W Lamers, G P van Berge Henegouwen
}

\begin{abstract}
Repeated daily injections of the somatostatin analogue, octreotide (SMS201-995, Sandostatin) are an effective treatment for acromegaly, but lead to gall stone formation in about $50 \%$ of cases during longterm treatment. This is probably because of impaired gall bladder contraction. This study examined whether the timing of intermittent injections in relation to meals, or alternatively, continuous 24 hour subcutaneous octreotide infusion (CSOI) might avert adverse effects on gall bladder contraction. In six patients with active acromegaly, gall bladder volume, plasma cholecystokinin (CCK), and pancreatic polypeptide (PP) were measured in the fasting state and after consumption of a fatty meal. Measurements were made on five separate days: (a) without treatment, (b) 45 minutes after $100 \mu \mathrm{g}$ octreotide given subcutaneously, (c) four hours after $100 \mu \mathrm{g}$ octreotide given subcutaneously, (d) eight hours after $100 \mu \mathrm{g}$ octreotide given subcutaneously, and (e) during CSOI of $300 \mu \mathrm{g} / 24 \mathrm{~h}$ for two weeks. Without treatment, postprandial gall bladder contraction was $86 \cdot 2(2 \cdot 1 \%)$. Fasting gall bladder volume increased after octreotide injection and was almost doubled during CSOI. Octreotide injections impaired postprandial gall bladder contraction as well as CCK and PP release for at least four hours. Eight hours after injection and during CSOI, postprandial gall bladder contraction was partly restored $(43.4 \%$ and $50.8 \%$ respectively). Postprandial CCK release was normal at eight hours after injection but very low during-CSOI. PP release was suppressed by each mode of octreotide treatment. This study indicates that octreotide injections impair postprandial gall bladder contraction for at least four hours. Eight hours after injection and during CSOI, gall bladder contraction is partly restored.

(Gut 1993; 34: 808-813)
\end{abstract}

Intermittent subcutaneous treatment with a longacting somatostatin analogue, octreotide (SMS201-995, Sandostatin) is an effective treatment for patients with acromegaly. ${ }^{1-3}$ Octreotide is usually given by intermittent subcutaneous injection of $100-500 \mu \mathrm{g}$ twice daily or three times daily. Continuous subcutaneous octreotide infusion (CSOI) of $300-1500 \mu \mathrm{g} / 24 \mathrm{~h}$ is probably more effective in suppressing growth hormone secretion. ${ }^{45}$ An important side effect of longterm octreotide treatment with intermittent injections is a high incidence, up to $50 \%$, of gall stone formation during one year of treatment. ${ }^{6-9}$ The rate of gall stone formation during CSOI has yet to be discovered, but is probably lower. ${ }^{4} \mathrm{~A}$ high occurrence of gall stones is also found in patients with somatostatinoma, the natural equivalent of longterm somatostatin treatment. ${ }^{10}$ Like natural somatostatin, octreotide inhibits postprandial gall bladder contraction, release of cholecystokinin (CCK), and pancreatic polypeptide (PP) when given just before a meal. ${ }^{11-13}$ Impaired postprandial gall bladder contraction is a risk factor for gall stone formation. ${ }^{14-16}$

We examined the effect of varying the intervals between octreotide injection and meal ingestion on fasting and postprandial gall gladder motility and on plasma CCK and PP concentrations in patients with acromegaly. These findings were used to see whether appropriate timing of octreotide injections with respect to meal ingestion might avert impaired gall bladder contraction. In addition, we examined the effect of CSOI on fasting and postprandial gall bladder motility and hormone release in these patients.

\section{Patients and methods}

SUBJECTS

Six patients with active acromegaly, requiring octreotide treatment, were enrolled in the study. All patients had typical clinical features of the acromegaly syndrome, high circulating growth hormone concentrations, which were not suppressed below $2 \mu \mathrm{g} / \mathrm{l}$ after an oral glucose load, and insulin like growth factor-1 (IGF-1) or somatomedin-C plasma concentrations above the mean 2 (SD) for age. Table I shows patient characteristics. Ultrasound examination of the gall bladder, bile ducts, and liver was performed before the study and showed no stones, sludge, or other abnormalities. None of the patients had had abdominal surgery previously. None of the patients were pregnant at the time of the study or had taken any drug which could potentially interfere with gall bladder motility. Body weight was stable during the three months preceding the study. All patients gave written informed consent. The study protocol was approved by the ethical committee of our hospital.

\section{PROTOCOL}

Postprandial gall bladder contraction as well as plasma CCK and PP concentrations were assessed on five separate days with at least one day in between to allow for degradation of 
TABLE I Characteristics of six patients with acromegaly. Insulin like growth factor-1 (IGF-1) concentrations were verified before inclusion in the study

\begin{tabular}{|c|c|c|c|c|c|}
\hline Patient & Sex & $\begin{array}{l}\text { Age } \\
(y)\end{array}$ & $\begin{array}{l}\text { Body } \\
\text { weight } \\
\text { (kg) }\end{array}$ & $\begin{array}{l}I G F-1 \\
(n g / m l)\end{array}$ & $\begin{array}{l}\text { Previous treatment (length of treatment) } \\
\text { (month) }\end{array}$ \\
\hline $\begin{array}{l}\mathbf{A} \\
\mathbf{B}\end{array}$ & $\begin{array}{l}\mathbf{F} \\
M\end{array}$ & $\begin{array}{l}31 \\
45\end{array}$ & $\begin{array}{r}89 \\
108\end{array}$ & $\begin{array}{r}708 \\
1031\end{array}$ & $\begin{array}{l}\text { None } \\
\text { PMS } \\
\text { irradiation } \\
\text { bromocriptine (108) }\end{array}$ \\
\hline C & $\mathbf{F}$ & 52 & 83 & 583 & $\begin{array}{l}\text { PMS } \\
\text { irradiation } \\
\text { octreotide thrice daily }(6)\end{array}$ \\
\hline $\begin{array}{l}\text { D } \\
\text { E }\end{array}$ & $\begin{array}{l}M \\
F\end{array}$ & $\begin{array}{l}61 \\
55\end{array}$ & $\begin{array}{l}83 \\
78\end{array}$ & $\begin{array}{l}340 \\
294\end{array}$ & $\begin{array}{l}\text { Octreotide thrice daily (31) } \\
\text { PMS } \\
\text { irradiation } \\
\text { octreotide thrice daily (10) }\end{array}$ \\
\hline $\mathrm{F}$ & $\mathbf{M}$ & 28 & 97 & 570 & $\begin{array}{l}\text { octreotide thrice daily (10) } \\
\text { Octreotide four times daily (28) }\end{array}$ \\
\hline
\end{tabular}

Patients $\mathrm{C}$ to $\mathrm{F}$ were treated with subcutaneous octreotide injections of $100 \mu \mathrm{g}$ until two weeks before the study started. PMS = pituitary micro surgery.

octreotide $\left(T_{1 / 2}=80-100\right.$ minutes). ${ }^{17}$ The first measurement was made after two weeks without any treatment. The second, third, and fourth measurement (on separate days) started at 45 minutes, four hours, and eight hours respectively after a single subcutaneous injection of $100 \mu \mathrm{g}$ octreotide (Sandostatin, Sandoz AG, Basle, Switzerland). The fifth measurement was made after two weeks of continuous subcutaneous treatment with $300 \mu$ g octreotide $/ 24 \mathrm{~h}$ with an ambulatory pump (CADD-1 Ambulatory Infusion Pump, Pharmacia Deltec Inc, St Paul, USA). This measurement was taken while the pump was giving octreotide.

\section{Measurements}

After an overnight fast, gall bladder volume was measured by real time ultrasonography (SDR 1500, Philips Ultrasound Inc, California, USA: $5.0 \mathrm{MHz}$ transducer). Sagittal and transverse scans of the gall bladder at its largest dimensions were obtained. Subsequently, after consumption of a test meal, gall bladder images were made every 15 minutes for 2 hours. These images were stored on video tape and processed by a MS-DOS computer, using a video grabber, and processing software (IBAS, Kontron $\mathrm{GmbH}$, Munich, Germany). Gall bladder volume was calculated with the sum of cylinders method. ${ }^{18} 19$ The test meal consisted of 1 slice of white bread, $5 \mathrm{~g}$ margarine, $50 \mathrm{~g}$ cheese, 1 boiled egg, $200 \mathrm{ml}$ yoghurt, and $50 \mathrm{~g}$ glucose. This is equivalent to $30 \mathrm{~g}$ fat, $30 \mathrm{~g}$ protein, and $70 \mathrm{~g}$ carbohydrate and gives a physiologic stimulation of gall bladder contraction and cholecystokinin release. Fasting volume (mean of measurements at 15 and 0 minutes before test meal; $\mathrm{V}_{0}$ in $\mathrm{ml}$ ) and resi- dual postprandial volume were measured as characteristic of gall bladder motility. Residual gall bladder volume $\left(\mathrm{V}_{\text {res }}\right.$ in $\left.\mathrm{ml}\right)$ was defined as the resulting volume after maximum response to a test meal. In gall bladder filling after a test meal, $V_{\text {res }}$ reflects maximum gall bladder volume. As indices of postprandial gall bladder contraction, maximum decrement of gall bladder volume in $\mathrm{ml}$ and percentage $\left(\Delta \mathrm{V}_{\max } \mathrm{ml}\right.$ and $\left.\Delta V_{\max } \%\right)$ and integrated gall bladder contraction (expressed as $\mathrm{ml} .120 \mathrm{~min}$ ) were calculated.

Blood samples were taken in the fasting state, at -15 and 0 minutes and, after consumption of the test meal, every 15 minutes for 2 hours. Blood was collected in ice chilled tubes. Plasma was stored at $-20^{\circ} \mathrm{C}$ until analysis. CCK and PP plasma concentrations were measured by sensitive and specific radioimmunoassays, as described previously. ${ }^{2021}$ Indices of CCK and PP release were basal concentration (mean of concentrations at -15 and 0 minutes), maximum increase $(\triangle C C K$ and $\triangle P P$ ), and integrated CCK and PP release (expressed as pmol.1 ${ }^{-1} .120$ $\mathrm{min})$. Plasma octreotide concentrations $(\mathrm{pg} / \mathrm{ml})$ were assessed by radioimmunoassay (Sandoz, Basle, Switzerland), immediately before consumption of the test meal (at 0 minutes) for measurements at 45 minutes, 4 hours, and 8 hours after subcutaneous octreotide injection. Plasma octreotide concentrations during CSOI were measured in the fasting state and, after consumption of the test meal, every 30 minutes for two hours.

\section{Statistical analysis}

Results are shown as mean (SEM). Differences between the effects of the five experimental conditions on gall bladder volume, hormone release, and octreotide values were assessed by two way repeated measures of analysis of variance. When a statistically significant difference was detected, results were further analysed by Fishers's LSD test. Statistical significance was defined as a two tailed probability of less than $0 \cdot 05 .{ }^{22}$

\section{Results}

\section{GALL BLADDER CONTRACTION}

Table II shows indices of gall bladder contraction and Figure 1 shows gall bladder contraction curves. Without treatment, postprandial gall bladder contraction was $86 \cdot 2(2 \cdot 1) \%$ or $36 \cdot 2(5 \cdot 7)$

TABLE II Indices of gall bladder contraction, measured on five separate days: without medication, at 45 minutes, 4 hours, and 8 hours after subcutaneous injection (SC) of $100 \mu \mathrm{g}$ octreotide and after two weeks of continuous subcutaneous octreotide injection (CSOI) of $300 \mu g / 24 \mathrm{~h}$

\begin{tabular}{|c|c|c|c|c|c|}
\hline Indices & No medication & $\begin{array}{l}45 \text { minutes after } 100 \\
\mu \mathrm{g} S C \text { injection }\end{array}$ & $\begin{array}{l}4 \text { hours after } 100 \\
\mu g S C \text { injection }\end{array}$ & $\begin{array}{l}8 \text { hours after } 100 \\
\mu g S C \text { injection }\end{array}$ & $\begin{array}{l}\text { Continuous SC } \\
\text { infusion } 300 \mu g / 24 h\end{array}$ \\
\hline $\begin{array}{l}\mathrm{V}_{0}(\mathrm{ml}) \\
\mathrm{V}_{\mathrm{res}}(\mathrm{ml}) \\
\Delta \mathrm{V}_{\max }(\mathrm{ml}) \\
\Delta \mathrm{V}_{\max }(\%) \\
\text { AUC contraction }(\mathrm{ml} .120 \mathrm{~min})\end{array}$ & $\begin{array}{c}42 \cdot 1(6 \cdot 3) \ddagger \| \\
5 \cdot 6(1 \cdot 3) \dagger \neq \| \\
36 \cdot 2(5 \cdot 7) \dagger \ddagger \\
86 \cdot 2(2 \cdot 1) \dagger \ddagger \$ \\
-3134(408 \cdot 3) \dagger \ddagger\end{array}$ & $\begin{array}{c}52 \cdot 3(10 \cdot 0) \| \\
57 \cdot 5(10 \cdot 0)^{\star} \\
-5 \cdot 1(5 \cdot 0)^{\star} \delta\|\| \\
-14 \cdot 8(12 \cdot 5)^{\star}\|\| \\
236 \cdot 2(233 \cdot 5)^{\star} \|\end{array}$ & $\begin{array}{c}57 \cdot 2(10 \cdot 6)^{\star} \| \\
58 \cdot 7(14 \cdot 0)^{\star} \\
-1 \cdot 5(8 \cdot 6)^{\star} \delta \| \\
1 \cdot 2(14 \cdot 6)^{\star} \mid \| \\
-32 \cdot 3(622 \cdot 6)^{\star}\end{array}$ & $\begin{array}{c}50 \cdot 0(7 \cdot 9) \| \\
26 \cdot 9(6 \cdot 7) \dagger \ddagger \\
23 \cdot 0(7 \cdot 4) \dagger \ddagger \\
43 \cdot 4(10 \cdot 4)^{\star} \dagger \ddagger \\
-1711(651.8) \dagger\end{array}$ & $\begin{array}{c}81 \cdot 5(9 \cdot 2)^{\star} \dagger \ddagger \emptyset \\
41 \cdot 8(10 \cdot 6)^{\star} \\
39 \cdot 7(6 \cdot 3) \dagger \ddagger \\
50 \cdot 8(8 \cdot 5) \dagger \ddagger \\
-2821(917 \cdot 6) \dagger \ddagger\end{array}$ \\
\hline
\end{tabular}

Significant difference compared with: *before treatment, $\uparrow 45$ minutes after injection, $¥ 4$ hours after injection, $\$ 8$ hours after injection, $\|$ two weeks continuous subcutaneous octreotide infusion.

$\mathrm{V}_{0}=$ fasting volume, $\mathrm{V}_{\text {res }}=$ residual volume, $\Delta \mathrm{V}_{\max }=$ maximal decrement of gall bladder volume, AUC contraction=integrated gall bladder contraction. 


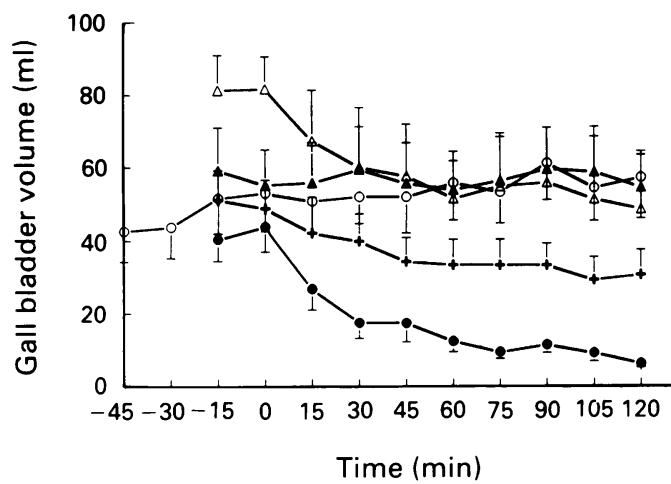

Figure 1: Gall bladder volume before and after a test meal during five experimental conditions. $\mathrm{O}=$ before treatment, $\mathrm{O}=$ 45 minutes after injection of $100 \mu \mathrm{g}$ octreotide, $\Delta=4$ hours after injection, $+=8$ hours after injection, $\triangle=$ during continuous subcutaneous octreotide infusion of $300 \mu \mathrm{g} / 24 \mathrm{~h}$ for two weeks.

ml. Forty five minutes and four hours after subcutaneous octreotide injection (measured on separate days), postprandial gall bladder contraction was stopped. Eight hours after octreotide injection, postprandial gall bladder contraction was partially restored. Fasting gall bladder volume increased after injections, compared with the volume before treatment. After two weeks of CSOI of $300 \mu \mathrm{g} / 24 \mathrm{~h}$, fasting gall bladder volume had increased almost twofold to $81.5(9 \cdot 2) \mathrm{ml}$ whereas postprandial gall bladder contraction was $50 \cdot 8(8 \cdot 5) \%$ or $39 \cdot 7(6 \cdot 3) \mathrm{ml}$. Eight hours after injection of octreotide and after two weeks of CSOI, $\Delta \mathrm{V}_{\max } \mathrm{ml}$ (as index for the amount of bile expelled to the duodenum during a meal) was not significantly different compared with that of gall bladder contraction without treatment (Fig 2).

\section{CHOLECYSTOKININ AND PP RELEASE}

Table III shows indices of plasma CCK and PP release. Basal CCK concentrations did not change during octreotide treatment. Postprandial CCK release was suppressed for at least four hours after injection (Fig 3). Eight hours after injection, integrated postprandial CCK release was not significantly different compared with the first measurement, without treatment (Fig 4). During CSOI, postprandial CCK release was suppressed. Integrated CCK release was only $46 \cdot 0(22 \cdot 5)$ pmol CCK. $1^{-1} .120 \mathrm{~min}$ compared with $256 \cdot 8(30 \cdot 1)$ pmol CCK. $1^{-1} .120 \mathrm{~min}$ without treatment. Basal PP concentrations and postprandial PP release were suppressed by

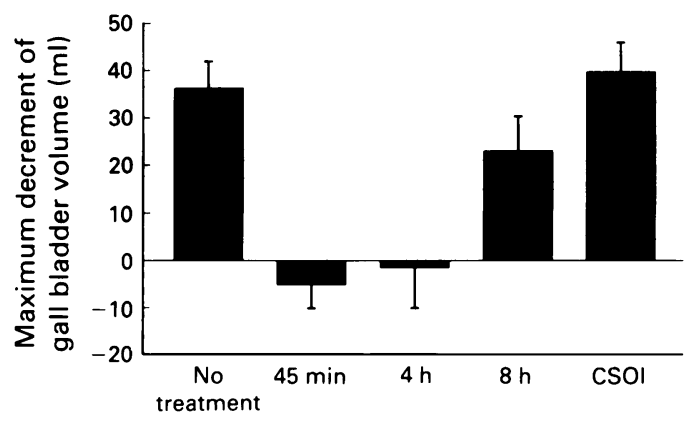

Figure 2: Maximum decrement of gall bladder volume $(\mathrm{ml})$ after a test meal, during five different experimental conditions. 45 minutes, 4 hours, and 8 hours refer to the time when the meal was given after subcutaneous injection of $100 \mu \mathrm{g}$ octreotide. $C S O I=$ gall bladder contraction during continuous subcutaneous octreotide infusion.

intermittent injections as well as by CSOI (Fig 5).

PLASMA OCTREOTIDE CONCENTRATION

Table III shows plasma octreotide concentrations. As expected, plasma octreotide concentrations were lowest eight hours after injection. During CSOI, octreotide concentrations were comparable with values at four hours after injection. Octreotide concentrations during CSOI did not change for two hours after meal consumption (results not shown).

\section{Discussion}

This study showed that fasting gall bladder volume increased after treatment with octreotide. Fasting gall bladder volume had virtually doubled from $42.1 \mathrm{ml}$ in octreotide free conditions to $81.5 \mathrm{ml}$ after two weeks of CSOI. Increased fasting gall bladder volume during octreotide might be a result of decreased gall bladder muscle tone or because of the absence of interdigestive gall bladder contraction, which takes place in the fasting state, in close association with the intestinal migrating motor complex. ${ }^{23}$ Decreased sphincter of oddi function might also account for increased fasting volume. ${ }^{24}$ In comparison with a control group of 20 normal subjects, studied in our laboratory, patients with acromegaly had large fasting volumes, even without treatment $(18.9(1.6 \mathrm{ml}) v$ $42 \cdot 1(6.3 \mathrm{ml}) ; \mathrm{p}<0.002) .{ }^{25}$ Similarly, increased fasting gall bladder volumes have been reported in obese, tall, and muscular subjects. ${ }^{26}$ Therefore, increased fasting volumes in patients with

TABLE III Basal cholecystokinin (CCK) and pancreatic polypeptide (PP) concentrations (pmol/l), maximum increase, integrated release ( $p$ mol/l $\times 120 \mathrm{~min})$, and plasma octreotide concentrations $(\mathrm{pg} / \mathrm{ml})$ before treatment, at $45 \mathrm{minutes,} 4 \mathrm{hours,} \mathrm{and}$ 8 hours after subcutaneous injection of $100 \mu \mathrm{g}$ octreotide and after two weeks of CSOI of $300 \mu \mathrm{g} / 24 \mathrm{~h}$

\begin{tabular}{|c|c|c|c|c|c|}
\hline Indices & No medication & $\begin{array}{l}45 \text { minutes after } 100 \\
\mu \mathrm{g} S \mathrm{C} \text { injection }\end{array}$ & $\begin{array}{l}4 \text { hours after } 100 \\
\mu g S C \text { injection }\end{array}$ & $\begin{array}{l}8 \text { hours after } 100 \\
\mu \mathrm{g} S \mathrm{C} \text { injection }\end{array}$ & $\begin{array}{l}\text { Continuous } S C \\
\text { infusion } 300 \mu \mathrm{g} / 2+\mathrm{h}\end{array}$ \\
\hline $\begin{array}{l}\text { Basal CCK } \\
\text { Maximum increase CCK } \\
\text { AUC CCK } \\
\text { Basal PP } \\
\text { Maximum increase PP } \\
\text { AUC PP } \\
\text { Octreotide }\end{array}$ & $\begin{array}{c}2 \cdot 0(0 \cdot 3) \\
2 \cdot 6(0 \cdot 2)+\ddagger \S \| \\
256 \cdot 8(30 \cdot 1)+\ddagger \\
26 \cdot 1(3 \cdot 2)+\ddagger \S \\
98 \cdot 3(13 \cdot 9)+\ddagger \S \| \\
8738 \cdot 8(1458 \cdot 6) \dagger \ddagger \S \| \\
-\end{array}$ & $\begin{array}{c}1 \cdot 6(0 \cdot 3) \\
0 \cdot 4(0 \cdot 2)^{\star} \mathbb{}\|\| \\
-15 \cdot 5(16 \cdot 2)^{\star} \neq \Phi \\
13 \cdot 6(1 \cdot 9)^{\star} \| \\
0 \cdot 2(0 \cdot 1)^{\star} \\
-367 \cdot 5(69 \cdot 0)^{\star} \\
2089 \cdot 5(264 \cdot 6) \neq \Phi \|\end{array}$ & $\begin{array}{c}1 \cdot 8(0 \cdot 4) \\
1 \cdot 0(0 \cdot 2)^{\star} \S \| \\
76 \cdot 0(20 \cdot 8)^{\star}+5 \\
9 \cdot 6(1 \cdot 5)^{\star} \\
2 \cdot 4(0 \cdot 8)^{\star} \\
-47 \cdot 5(50 \cdot 6)^{\star} \\
857 \cdot 2(67 \cdot 1) \dagger\end{array}$ & $\begin{array}{c}1 \cdot 9(0 \cdot 3) \\
2 \cdot 0(0 \cdot 2)^{\star}+\dagger \neq \| \\
192 \cdot 8(30 \cdot 0) \dagger \neq \| \\
9 \cdot 1(1 \cdot 6)^{\star} \\
4 \cdot 6(1 \cdot 6)^{\star} \\
217 \cdot 5(109 \cdot 3)^{\star} \\
320 \cdot 0(77 \cdot 2)+\|\end{array}$ & $\begin{array}{c}1 \cdot 8(0 \cdot 2) \\
0 \cdot 7(0 \cdot 1)^{\star}+ \pm j \\
\left.46 \cdot 0(22 \cdot 5)^{\star}\right\rfloor \\
7 \cdot 8(1 \cdot 2)^{\star} \dagger \\
9 \cdot 6(5 \cdot 8)^{\star} \\
655 \cdot 0(+31 \cdot 9)^{\star} \\
1025 \cdot 2 \cdot 270 \cdot 8)+0\end{array}$ \\
\hline
\end{tabular}

Significant difference compared with: *before treatment, $\uparrow 45$ minutes after injection, $\ddagger 4$ hours after injection, $\$ 8$ hours after injection. |lwo weeks continuous subcutaneous octreotide infusion. 


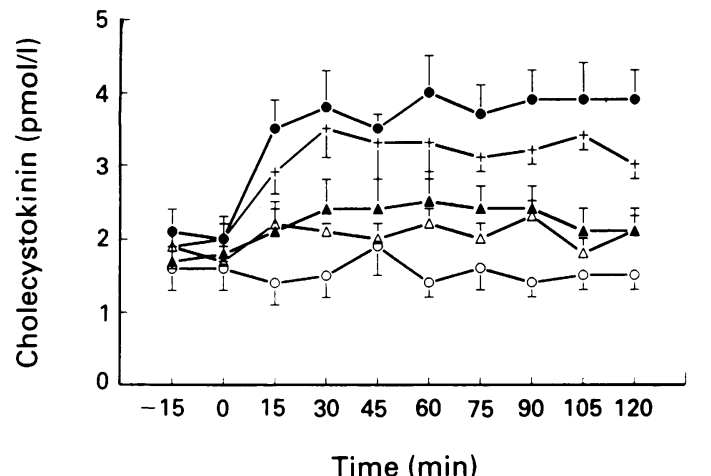

Figure 3: Plasma cholecystokinin concentrations (pmol/l) before and after ingestion of a test meal. For symbols see Fig 1.

acromegaly might be explained by their large body size.

We found that patients with acromegaly not receiving treatment, were able to contract their gall bladder almost completely after a meal. This is in agreement with other studies. ${ }^{127}$ It would seem that acromegaly as such does not directly impair gall bladder contraction. Our study also showed that postprandial gall bladder contraction was suppressed for at least four hours after octreotide injection. Delayed gastric emptying is not responsible for this finding since octreotide, in contrast with somatostatin, slightly accelerates gastric emptying of a mixed meal. ${ }^{28}$ Like others, we saw postprandial gall bladder filling rather than contraction at 45 minutes and four hours after injection. ${ }^{12}$ At eight hours after injection, postprandial gall bladder contraction (ml) was not significantly different compared with contraction without treatment or with contraction after two weeks of CSOI. This could be because of the small number of patients studied, but it is in agreement with the results of Hopman et $a l$, who measured postprandial gall bladder contraction in patients on longterm (six months) intermittent injection treatment. At eight hours after the last injection they found $17 \cdot 0 \mathrm{ml}$ emptying, which was not significantly different from postprandial gall bladder contraction without treatment. ${ }^{27}$

Low plasma octreotide concentration and increased fasting volume may explain improved gall bladder contraction. Gall bladder contraction during longterm treatment was still greatly

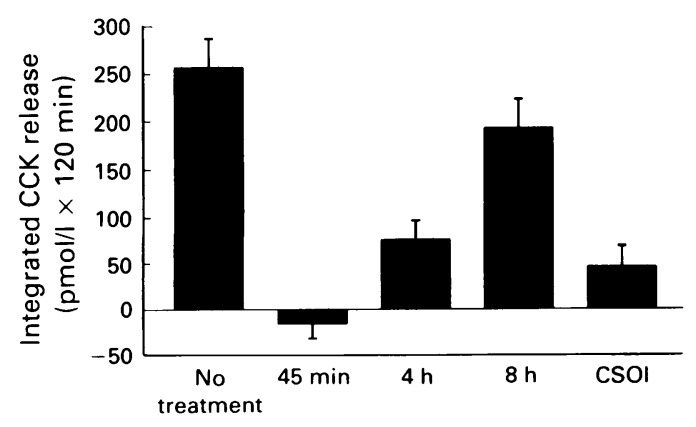

Figure 4: Integrated CCK release (pmol/l $\times 120$ min) during five different experimental conditions. 45 minutes, 4 hours, and 8 hours refer to the time when the meal was given after subcutaneous injection of $100 \mu \mathrm{g}$ octreotide. CSOI = gall bladder contraction during continuous subcutaneous octreotide infusion. CCK release during continuous infusion is remarkably low.

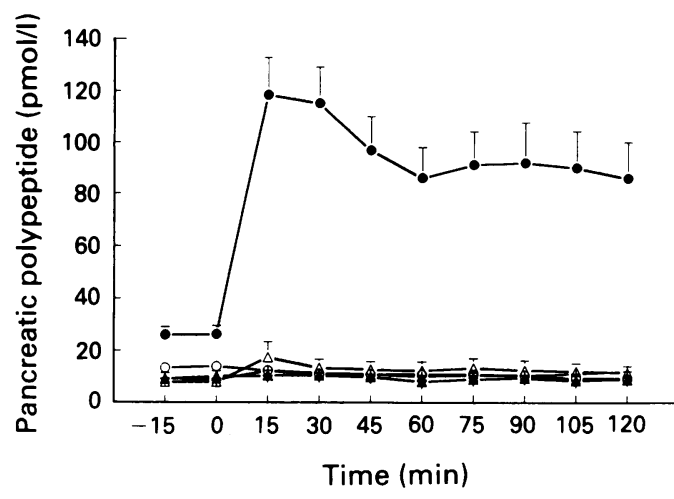

Figure 5: Plasma pancreatic polypeptide concentrations (pmol/l) before and after ingestion of a test meal during five different experimental conditions. For symbols see Fig 1. PP release is suppressed by each octreotide administration mode and even below basal values.

suppressed (19\%) at 45 minutes after injection. ${ }^{27}$ This study suggests that CSOI $(50 \cdot 8 \%$ contraction) or adequate timing of injections with respect to meals might, at least partially, preserve gall bladder contraction and thereby might reduce the risk of gall stone formation.

After each mode of octreotide treatment, postprandial residual gall bladder volume increased. In pregnancy ${ }^{29}$ and obesity, ${ }^{30}$ increased fasting and postprandial residual gall bladder volumes are associated with increased risk of gall stone formation. In tall and muscular subjects, fasting and residual gall bladder volumes are also increased but, as far as known, without increased risk of gall stone formation. ${ }^{26}$ Therefore, the role of increased fasting and residual gall bladder volume - as described in this study of patients with acromegaly receiving octreotide treatment - in the formation of gall stones remains uncertain.

The effect of octreotide on gall bladder motility may not be crucial in the formation of gall stones. Somatostatin and octreotide also have an effect on bile composition. In experiments with animals, bile salt independent canalicular flow is reduced and biliary lipid concentration is enhanced. ${ }^{31-35}$ This increases biliary cholesterol content and favours nucleation of cholesterol monohydrate crystals. Potential differences in this respect between intermittent octreotide injection and CSOI have yet to be studied.

Gall bladder contraction is regulated by an interaction of the myenteric plexus with intestinal hormones. CCK is important for mediating postprandial gall bladder contraction and acts in physiological doses by the cholinergic neurons of the plexus, as shown in guinea pigs. ${ }^{36}$ In the same species, in vitro, somatostatin does not inhibit gall bladder contraction induced by CCK octapeptide or acetylcholine ${ }^{37}$ but it inhibits electrically induced gall bladder contraction, probably by a reduction of acetylcholine release. ${ }^{38}$ The same finding was made in dogs. ${ }^{39}$ This indicates that somatostatin - and probably also octreotide - has no direct effect on the gall bladder but exerts its inhibitory action by the myenteric plexus. Moreover, octreotide inhibits the release of CCK from the duodenum.

PP is produced in the pancreas and its release in under cholinergic control and can be evoked 
by a meal. PP inhibits gall bladder contraction by an inhibiting action on cholinergic pathways. ${ }^{40}$ Postprandial PP release was at a maximum in the untreated state. After each injection of octreotide, fasting PP concentrations and postprandial PP release were suppressed, even below basal values. Therefore, it is concluded that increased fasting gall bladder volumes and inhibition of postprandial gall bladder contraction during octreotide treatment are not mediated by PP. Plasma octreotide and PP concentrations confirmed patient compliance to the study protocol.

Acromegaly patients generally use three octreotide injections daily, usually given before breakfast in the morning (8:00), afternoon (16:00), and late in the evening (24:00). This study suggests that if the early morning injection is taken after breakfast, the gall bladder can empty partially $(43 \cdot 4 \%)$. Gall bladder contraction during lunch and dinner (within 4 to 6 hours of the early morning and afternoon injection), however, remains suppressed. Good gall bladder contraction after breakfast is important because gall bladder bile has the highest cholesterol saturation index and concentration at that time and cholesterol crystals might precipitate easily. ${ }^{41}$ In the subgroup of patients who are treated with two injections daily, adequate gall bladder contraction might also be achieved after dinner. At eight hours after injection, about $70 \%$ of maximum gall bladder contraction was achieved at 45 minutes after the test meal. This might suggest that octreotide injections should be given at least 45 minutes after a meal. During CSOI, postprandial gall bladder contraction is partially preserved during all meals.

In conclusion, this study shows that postprandial gall bladder contraction and CCK and PP release are greatly impaired for at least four hours after injection of octreotide. Eight hours after octreotide injection, gall bladder contraction is partially restored and CCK release is completely restored. Also during CSOI, postprandial gall bladder contraction is partially restored while CCK release remains low. Prospective studies should show whether appropriate timing of octreotide injections with respect to meal ingestion, or alternative treatment schedules, like CSOI, might lessen the risk of gall stone formation during long term octreotide treatment.

The authors thank Dr M Terlou for calculation of gall bladder volumes, Dr M S van Leeuwen, and R Mëyer for ultrasonographic assistance, and Dr J van Bree, Sandoz, Switzerland, for octreotide measurements. This study was supported by The Netherlands Foundation for Medical Research (NWO-MW) grant no 900-522. 106.

1 Plewe G, Beyer J, Krause U, Neufeld M, Del Pozo E. Longacting and selective suppression of growth hormone secretion by somatostatin analogue SMS 201-995 in acromegaly. Lancet 1984; ii: 782-4.

2 Lamberts SWJ, Uiterlinden P, Verschoor L, Dongen van KJ, Del Pozo E. Long acting treatment of acromegaly with the somatostatin analogue SMS 201-995. N Engl f Med 1985; 313: 1576-80.

3 Melmed S. Acromegaly. N Engl f Med 1990; 322: 966-77.

4 Tauber JP, Babin T, Tauber MT, Vigoni F, Bonafe A, Ducasse $M$, et al. Long-term effects of continuous subcutaneous infusion of the somatostatin analog octreotide in cutaneous infusion of the somatostatin analog octreotide in 68: $917-24$.

5 Christensen SE, Weeke J, Orskov H, Moller N, Flyvbjerg A Harris AG, et al. Continuous subcutaneous pump infusion of Harris AG, et al. Continuous subcutaneous pump infusion of somatostatin analogue SMS $201-995$ versus subcutaneous
injection schedule in acromegalic patients. Clin Endocrinol injection schedule

6 Wass JA, Anderson JV, Besser GM, Dowling RH. Gall stones and treatment with octreotide for acromegaly [Letter]. $B M \mathcal{F}$ 1989; 229: 1162-3.
7 McKnight JA, McCane DR, Atkinson AB, Crothers JG Changes in glucose tolerance and development of gallstones during high dose treatment with octreotide for acromegaly. BMF 1989; 299: 604-5.

8 Ho KY, Weissberger AJ, Marbach P, Lazarus L. Therapeutic efficacy of the somatostatin analog SMS 201-995 (Octreotide) in acromegaly. Ann Intern Med 1990; 112 173-81.

9 Buscail L, Tauber JP, Escourrou J, Harris AG, Bousquet-Puel $\mathrm{C}$, Delvaux M, et al. Gallstone formation and occurrence of cholesterol monohydrate crystals in gallbladder bile of patients with long-term sandostatin treatment. Gastropatients with long-term

10 Krejs GJ, Orci L, Conlon JM, Ravazzola M, Davis GR, Raskin $\mathrm{P}$, et al. Somatostatinoma syndrome. N Engl f Med 1979; 301: 285-92.

11 Lembcke B, Creutzfeldt W, Schleser S, Ebert R, Shaw C, Koop I. Effect of the somatostatin analogue sandostatin (SMS 201-995) on gastrointestinal, pancreatic and biliary function and hormone release in normal men. Digestion 1987; 36: 108-24.

12 Van Liessum PA, Hopman WPM, Pieters GFFM, Jansen JBMJ, Smals AGH, Rosenbusch G, et al. Postprandia gallbladder motility during long term treatment with the acromegaly. F Clin Endocrinol Metab 1989; 69: 557-62.

13 Mitsukawa T. Takemura J, Nishizono F, Nakatsuru K, Ogho S, Matsukura S. Effects of atropine, proglumide, and S, Matsukura S. Effects of atropine, proglumide, and somatostatin analogue (SMS 201-995) on bombesin-induced gallbladder contraction and CC.

14 Fridhandler TM, Davison JS, Shaffer EA. Defective gallbladder contractility in the ground squirrel and prairie dog during the early stages of cholesterol gallstone formation. Gastroenterology 1983; 85: 830-6.

15 Pomeranz IS, Shaffer EA. Abnormal gallbladder emptying in a subgroup of patients with gallstones. Gastroenterology 1985; 88: 787-91.

16 Brugge WR, Brand DL, Atkins HL, Lane BP, Abel WG Gallbladder dyskinesia in chronic acalculous cholecystitis. Dig Dis Sci 1986; 31: 461-7.

17 Kutz K, Nuesch E, Rosenthaler J. Pharmacokinetics of SMS201-995 in healthy subjects. Scand f Gastroenterol 1986; 21 (suppl 119): 65-72.

18 Everson GT, Braverman DZ, Johnson ML, Kern F Jr. A critical evaluation of real-time ultrasonography for the study of gallbladder volume and contraction. Gastroenterology 1980; 79: 40-6.

19 Stolk MFJ, Erpecum van KJ, Berge Henegouwen van GP, Kesselring OFHW, Hopman WPM. Gallbladder volume and contraction measured by sum-of-cylinders method compared with ellipsoid and area-length methods. Acta Radiol 1990; 31: 591-6.

20 Jansen JBMJ, Lamers CBHW. Radioimmunoassay of cholecystokinin in human tissue and plasma. Clin Chim Acta 1983; 131: 305-16.

21 Jong de AJL, Singer MV, Lamers CBHW. Effect of rabbit antipancreatic polypeptide serum on postprandial pancreatic exocrine secretion in dogs. Gastroenterology 1986; 90: 1926-31.

22 Armitage P, Berry G. Statistical methods in medical research. 2nd ed. Oxford: Blackwell Scientific, 1987.

23 Marzio L, Neri M, Capone F, Di Felice F, De Angelis C, Mezzetti A, et al. Gallbladder contraction and its relation to interdigestive duodenal motor activity in normal human subjects. Dig Dis Sci 1988; 33: 540-4.

24 Ahrendt SA, McGuire GE, Lillemoe KD, Trias M, Kaloo A, Pitt HA. Somatostatin inhibits sphincter of Oddi motility. Gastroenterology 1990; 98: A242.

25 Van Erpecum KJ, van Berge Henegouwen GP, Stolk MFJ, Hopman WPM, Jansen JMBJ, Lamers CBHW. Fasting gallbladder volume, postprandial emptying and cholecystokinin release in gallstone patients and normal subjects. fHin repatol 1992; 14: 194-202.

26 Vezina WC, Paradis RL, Grace DM, Zimmer RA, Lamont $\mathrm{DD}$, Rycroft $\mathrm{KM}$, et al. Increased volume and decreased emptying of the gallbladder in large (morbidly obese, tall normal, and muscular normal) people. Gastroenterology 1990; 98: 1000-7.

27 Hopman WPM, Liessum van PA, Pieters GFFM, Jansen JBMJ, Lamers CBHW, Rosenbusch G, et al. Effect of longterm octreotide treatment on gallbladder motility in acromegalic patients. Neth $\mathcal{F}$ Med 1991; 39: A18-9.

28 Fuessl HS, Carolan G, Williams G, Bloom SR. Effect of a longacting somatostatin analogue (SMS 201-995) on postprandial gastric emptying of ${ }^{99 \mathrm{~m}} \mathrm{Tc}$-tin colloid and mouth-to-caecum transit time in man. Digestion 1987; 36: 101-7.

29 Braverman DZ, Johnson ML, Kern F. Effects of pregnancy and contraceptive steroids on gallbladder function. $N$ Eng f Med 1980; 302: 362-4

30 Marzio L, Capone F, Neri M, Mezzetti A, De Angelis C, Cuccurullo F. Gallbladder kinetics in obese patients. Effect of a regular meal and low-calorie meal. Dig Dis Sci 1988; 33 : $4-9$.

31 Cucchiaro G, Branum GD, O'Dorisio T, Meyers WC. Effec of somatostatin and its analogue sandostatin on biliary lipid of somatostatin and its analogue sandostatin

32 Hanks JB, Kortz WJ, Andersen DK, Jones RS: Somatostatin suppression of canine fasting bile secretion. Gastroenterology suppression of canir.

33 Magnusson I, Einarsson K, Angelin B, Nyberg B, Bergström $\mathbf{K}$, Thulin $\mathbf{L}$. Effects of somatostatin on hepatic bile formation. Gastroenterology 1989; 96: 206-12. 
34 René E, Danzinger RG, Hofmann AF, Nakagaki $M$ Pharmacologic effect of somatostatin on bile formation in the dog. Gastroenterology 1983; 84: 120-9.

35 Ahrendt SA, McGuire GE, Pitt HA, Lillemoe KD. Why does somatostatin cause gallstones? Am 7 Surg 1991; 161: 177-83.

36 Takahashi T, May D, Owyang C. Cholinergic dependence of gallbladder response to cholecystokinin in the guinea pig in (1991; 261: G565-9.

37 Poitras P, Yamada T, Walsh JH. Absence of effect of somatostatin on the guinea pig gallbladder. Can $\mathcal{f}$ Physiol Pharmacol 1980; 58: 179-82.

38 Guillemin R. Somatostatin inhibits the release of acetylcholine induced electrically in the myenteric plexus. Endocrinology 1976; 99: 1653-4.

39 Milenov K, Rakovska A, Kalfin R, Mantovani M. Effect of somatostatin on the canine gallbladder motility. Neuropeptides 1990; 17: 75-80.

40 Adrian TE, Mitchenere P, Sagor G, Bloom SR. Effect of pancreatic polypeptide on gallbladder pressure and hepatic bile secretion. Amf Physiol 1982; 243: G204-7.

41 Northfield TC, Hofmann AF. Biliary lipid output during thre meals and an overnight fast. I. Relationship to bile acid poo size and cholesterol saturation of bile in gallstone and contro subjects. Gut 1975; 16: 1-17. 